\title{
Mild solutions for a multi-term fractional differential equation via resolvent operators
}

\author{
Yong-Kui Chang ${ }^{1}$ and Rodrigo Ponce ${ }^{2}$ \\ ${ }^{1}$ Xidian University \\ ${ }^{2}$ Universidad de Talca
}

July 17,2020

\begin{abstract}
This paper is concerned with multi-term fractional differential equations. With the help of the theory of fractional resolvent families, we establish the existence of mild solutions to a multi-term fractional differential equation.
\end{abstract}

\section{Hosted file}

Chang-Ponce-MMAS.pdf available at https://authorea.com/users/343798/articles/470385-mildsolutions-for-a-multi-term-fractional-differential-equation-via-resolvent-operators 